\title{
Controlled Hypotension for Functional Endoscopic Sinus Surgery: A Comparative study of Dexmedetomidine and Esmolol
}

\author{
Md. Shafiul Alam Shaheen ${ }^{1}$, A.K.M.Nurnobi Chowdhury ${ }^{2}$, Kawsar Sardar ${ }^{3}$, Mushfiqur Rahman ${ }^{4}$, \\ Sudhangshu Shekhar Biswas ${ }^{5}$, Ahmmad Taous ${ }^{6}$ \\ ${ }^{1}$ Assistant Professor, ${ }^{2}$ Professor, ${ }^{3}$ Professor, ${ }^{4}$ Junior Consultant, Department of Anesthesia \& Surgical \\ ICU, Ibrahim Medical College \& BIRDEM General Hospital, ${ }^{5}$ Associate Professor, Department of \\ Otolaryngology \& Head Neck Surgery, Ibrahim Medical College \& BIRDEM General Hospital, ${ }^{6}$ Associate \\ Professor, Department of ENT, Pabna Medical College. \\ Address of correspondence: Dr. Md. Shafiul Alam Shaheen, Registrar, Department of Anesthesia \& \\ Surgical ICU, Ibrahim Medical College \& BIRDEM General Hospital, Shahbagh, Dhaka, Bangladesh. \\ Email: drshafiul27@yahoo.com, mobile:+88 01912078807
}

\begin{abstract}
Background: Functional endoscopic sinus surgery (FESS) requires effective control of bleeding for better visibility of the operating field and reduced risk of injury to the optic nerve or the internal carotid artery. Controlled hypotension is a technique used to limit intraoperative blood loss to provide the best possible field for surgery.

Objectives: Our study is undertaken to evaluate the efficacy of dexmedetomidine as a hypotensive agent in comparison to esmolol in Functional Endoscopic Sinus Surgery (FESS).

Methods: Sixty (60) patients 20 - 50 years of age, ASA I/II scheduled for FESS were randomly assigned to two equal groups of 30 patients each. Patients of group D received dexmedetomidine $1 \mu \mathrm{g} / \mathrm{kg}$ over 10 min before induction of anesthesia followed by $0.4-0.8 \mu \mathrm{g} / \mathrm{kg} / \mathrm{hr}$ infusion during maintenance and group $\mathrm{E}$ received esmolol loading dose $1 \mathrm{mg} / \mathrm{kg}$ was infused over one min followed by $0.4-0.8 \mathrm{mg} / \mathrm{kg} / \mathrm{hr}$ infusion during maintenance to maintain mean arterial blood pressure (MAP) between ( $55-65 \mathrm{mmHg}$ ). The surgical field was assessed using Average Category Scale and average blood loss was calculated. Hemodynamic variables (MAP, HR); intraoperative fentanyl consumption and total recovery from anesthesia (Aldrete's score $\geq 9$ ) were recorded. Sedation score was determined at 10, 20, 30, 40 \& 60 min after tracheal extubation and time to first analgesic demand was also recorded.
\end{abstract}

\section{Results:}

In both group $D$ and group $E$ reached the desired MAP $(55-65 \mathrm{mmHg})$ with no inter group difference in MAP or HR. Mean intraoperative fentanyl consumption was significantly lower in group D than group $\mathrm{E}$. Recovery time to achieved Aldrete's score $\geq 9$ were significantly lower in group E compared with group $D$. 
The sedation score were significantly lower in group $E$ compared with group $D$ at 10 minutes, 20 minutes and 30 minutes postoperatively. Time to first analgesic demand was significantly longer in group D.

Conclusion: The result of this study showed that both dexmedetomidine and esmolol can be used as agents for controlled hypotension and are effective in providing ideal surgical field during FESS. But dexmedetomidine offers the advantage of inherent analgesic, sedative and anesthetic sparing effect.

Keywords: Controlled hypotension, dexmedetomidine, esmolol, functional endoscopic sinus surgery (FESS).

\section{Introduction}

Functional endoscopic sinus surgery (FESS) is the treatment of choice for acute and chronic sinus pathologies and nasal polyp. This surgical intervention restores the drainage pathways and aeration of the paranasal sinus. There are many benefits of a well-performed endoscopic sinus surgery with appropriate indications, but major complications of orbital hematoma, injury to the optic nerve, cerebrospinal fluid fistula, and intracranial injuries could occur as bleeding reduces the visibility of the operative field. To minimize these complications, effective control of bleeding at the surgical site is required.

Various techniques to minimize bleeding during sinus surgery are head elevation of $30^{\circ}$ (reverse Trendelenburg), infiltration or topical application of epinephrine, and electively controlled hypotension. Controlled hypotension is applied widely in several surgical interventions using different techniques. ${ }^{1}$ Benefits for controlled hypotension for FESS include reduction in blood loss with improved quality of surgical field. Various agents e.g. magnesium sulfate ${ }^{2}$, Vasodilators (sodium nitroprusside) ${ }^{3}$, nitroglycerine ${ }^{4}$, high dose of potent inhaled anesthetics $^{5}$, and beta adrenergic antagonist ${ }^{6}$ have been used to achieve controlled hypotension. Although these pharmacological agents effectively lower the blood pressure, they are associated with delayed recovery from inhaled anesthetics, resistance to vasodilator or tachyphylaxis, and cyanide toxicity from nitroprusside. Esmolol and nitroglycerine precisely control the blood pressure because of their rapid onset and short duration of action, but unambiguous hemodynamic monitoring is required. An infusion of $10-20 \mathrm{mg} / \mathrm{kg} / \mathrm{hr}$ remifentanyl is also useful, but is associated with

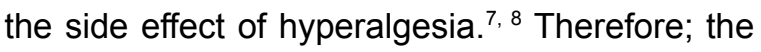
choice of an ideal agent is still controversial.

Esmolol is an ultrashort acting selective $\beta_{1}$ adrenergic antagonist that reduces heart rate and blood pressure. It has rapid onset of action of bolus IV injection and infusion. Upon termination of infusion gradual recovery of arterial blood pressure to the pre-infusion level occurred without development of rebound hypertension.

Dexmedetomidine is a potent highly selective $\alpha_{2}$ agonist, is used as an adjuvant to general anesthesia for sedation, analgesia, and 
hemodynamic stability with no postoperative respiratory depression. It is valuable because of its analgesic and anesthetic -sparing effects. ${ }^{9}$

Our study was designed to compare the efficacy and safety of dexmedetomidine or esmolol as a hypotensive agent in FESS with attention on the amount of blood loss, quality of the surgical field, recovery profile, and tolerability in adult patients.

\section{Methods}

This prospective randomized single-blind study was conducted from January 2016 to December 2016 at the department of Anesthesia \&Surgical ICU of BIRDEM General Hospital, Shahbagh, Dhaka, Bangladesh. After approval from hospital ethics committee and getting informed written consent to participate in the study, 60 patients aged 20-50 years, ASA physical status I \& II scheduled for elective FESS were recruited. Patients with recurrent sinus surgery, hypertension, coronary artery diseases and renal, hepatic or cerebral insufficiency and patients with coagulopathies or receiving drugs influencing blood coagulation were excluded from the study. All patients had bilateral nasal polyposis with opacity of all paranasal sinuses and they were assessed clinically in addition to ECG, chest X-ray and basal laboratory tests. The patients were divided into two groups randomly by envelop method where Group D received dexmedetomidine and group $E$ received esmolol.

In the operating room, two cannulae were inserted, one for infusion of dexmedetomidine or esmolol and the other for administration of fluids and other drugs. In group D, patients received loading dose of $1 \mu \mathrm{g} / \mathrm{kg}$ dexmedetomidine diluted in $10 \mathrm{ml} 0.9 \%$ normal saline infused over 10 minutes before induction of anaesthesia, followed by continuous infusion of $0.4-0.8$ $\mu \mathrm{g} / \mathrm{kg} / \mathrm{hr}$. in group $\mathrm{E}$, patients received esmolol as a loading dose $1 \mathrm{mg} / \mathrm{kg}$ was infused over one minute followed by continuous infusion of 0.4 $0.8 \mathrm{mg} / \mathrm{kg} / \mathrm{hr}$. in both groups infusion rate was titrated to maintain MAP within $55-65 \mathrm{mmHg}$. All patients were received general anaesthesia with induction dose of inj.Fentanyl 2 microgram $/ \mathrm{kg}$, inj. Propofol $1-2 \mathrm{mg} / \mathrm{kg}$ until loss of verbal response and muscle relaxant inj.Atracurium $0.5 \mathrm{mg} / \mathrm{kg}$. The required induction doses of Propofol were recorded. After induction, general anaesthesia maintained by $60 \% \mathrm{~N}_{2} \mathrm{O}$ and $40 \% \mathrm{O}_{2}$ and continuous infusion of Propofol @ 5mg/kg/hr. Incremental muscle relaxant was given every 20 minutes interval $1 / 4^{\text {th }}$ of the initial dose. In both groups, signs of inadequate anesthesia as increase in the blood pressure, heart rate or somatic responses as movement, tearing, or sweating were treated with additional dose of fentanyl. Respiratory rate and tidal volume were adjusted according to body weight to maintain normocapnia. Nitroglycerine was infused if these target limits could not be achieved with upper most doses. The drug infusion dose was decreased when targeted MAP was achieved. Patients were placed head elevation of $30^{\circ}$ (reverse Trendelenburg) to improve venous drainage. In both groups cottonoids soaked with epinephrine in a concentration of $1: 80,000$ was inserted into the nasal cavity to minimize the blood loss. Oropharyngeal pack was used in all patients. 
During the procedure, the quality of the surgical field was assessed by the surgeon every 10 minute interval. The same surgeon performed all operations to ensure consistency in the estimation of the surgical field. The surgeon was blinded to the hypotensive agent used. When MAP reached the desired range $55-65 \mathrm{mmHg}$ and was maintained for at least 10 minutes, the surgeon estimated the quality of the surgical field using a predefined category scale adopted from that of Fromme et al.(10).

Average category scale for assessment of intraoperative surgical field:

$0-$ No bleeding

1 - Slight bleeding: no suctioning of blood required

2 - Slight bleeding: occasional suctioning required. Surgical field not threatened

3 - Slight bleeding: frequent suctioning required. Bleeding threatens surgical field a few seconds after suction is removed

4 - Moderate bleeding: frequent suctioning required. Bleeding threatens surgical field directly after suction is removed

5 - Severe bleeding: constant suctioning required. Bleeding appears faster than can be removed by suction. Surgical field severely threatened and surgery not possible.

The ideal category scale values for surgical conditions were predetermined to be two and three. The total blood loss was measured from the suction apparatus. Infusion of the study drugs was stopped five minutes before the anticipated end of the surgery, and Propofol was stopped at the end of the surgery and residual neuromuscular blocked was antagonized with neostigmine $(0.05 \mathrm{mg} / \mathrm{kg})$ and atropine $(0.01 \mathrm{mg} / \mathrm{kg})$.

Monitoring included the heart rate, non-invasive blood pressure, continues ECG monitoring, $\mathrm{ETCO}_{2}$ concentration, $\mathrm{SPO}_{2}$, were recorded preoperatively (base line), post induction (after administration of hypotensive and anaesthetic agent), Intraoperatively ( $10,20,30,40 \& 60$ minutes), 5 minutes and 10 minutes after stoppage of hypotensive agents and lastly after recovery. Intraoperative fentanyl consumption and requirements for additional hypotensive agent (nitroglycerine) were recorded. After extubation and full recovery, patients were transferred to the postoperative word to be observed where time to first analgesic demand was recorded. Post operative recovery was evaluated using a modified Aldrete's Score (0 $10)^{11}$, and time needed to achieve $\geq 9$ was recorded. Sedation score ${ }^{12}$ was measured using the following scale at 10,20,30, 40 and 60 minutes after tracheal extubation. Sedation score: 1 - anxious, agitated, or restless; 2 cooperative, oriented, and tranquil; 3 responsive to commands; 4 - asleep, but with brisk response to light, glabellar tap, or loud auditory stimulus; 5 - asleep, sluggish response to glabellar tap, or auditory stimulus; and 6 asleep, no response. Patients were also asked 
about recalling intraoperative events or any sign of awareness.

Data processing and analysis
Statistical analysis was done using software SPSS (Statistical Package for Social Science), version 15. Demographic \& haemodynamic data were analysed using unpaired student t-test or chi-squire $\left(X^{2}\right)$. Statistically significance was set at $p$-value $<0.05$.

\section{Results}

Table I: Demographic variables

\begin{tabular}{|c|c|c|c|}
\hline & Group-D & Group-E & \\
\hline Variable & $\begin{array}{l}\text { Dexmedetomidine } \\
\qquad(n=30)\end{array}$ & Esmolol $(n=30)$ & $p$ value \\
\hline Age (years) & $34.40 \pm 11.12$ & $36.20 \pm 12.55$ & $0.56^{\mathrm{ns}}$ \\
\hline Sex (male/Female) & $11 / 19$ & $12 / 18$ & $0.78^{\text {ns }}$ \\
\hline Weight (kgs) & $53.67 \pm 8.13$ & $52.30 \pm 9.44$ & $0.55^{\mathrm{ns}}$ \\
\hline \multirow[t]{2}{*}{$\operatorname{ASA}(I / I I)$} & \multirow[t]{2}{*}{$21 / 9$} & \multirow[t]{2}{*}{$20 / 10$} & $0.78^{\text {ns }}$ \\
\hline & & & $0.63^{\text {ns }}$ \\
\hline \multirow[t]{2}{*}{ Duration of surgery (min) } & $90.03 \pm 9.44$ & $91.07 \pm 8.13$ & \\
\hline & & & $0.74^{\text {ns }}$ \\
\hline Estimated blood loss (ml) & $121.0 \pm 6.95$ & $123.03 \pm 7.85$ & \\
\hline
\end{tabular}


All values were presented as mean $\pm S D$ or in frequencies; ASA, American society of Anesthesiologists; Data were analysed using unpaired student t-test. Statistically significance was set at $p$-value $<0.05$. (NS=not significant).

Table II: Average category scale (0 -5) during hypotensive anesthesia periods

\begin{tabular}{|c|c|c|}
\hline & Group-D & Group-E \\
\hline Time during hypotensive & Dexmedetomidine & Esmolol $(n=30)$ \\
\hline Period & $(n=30)$ & \\
\hline $10 \mathrm{~min}$ & $2(1-3)$ & $2(2-3)$ \\
\hline $20 \mathrm{~min}$ & $2(2-3)$ & $2(1-2)$ \\
\hline $30 \mathrm{~min}$ & $2(1-2)$ & $2(1-3)$ \\
\hline $40 \mathrm{~min}$ & $2(1-3)$ & $2(1-2)$ \\
\hline $60 \mathrm{~min}$ & $2(1-2)$ & $2(1-2)$ \\
\hline
\end{tabular}

All values were presented as mean $\pm S D$ or in frequencies; Data were analysed using unpaired student ttest. Statistically significance was set at $p$-value $<0.05$. (NS=not significant, $S=$ significant). 
Table III: Recovery characteristics, sedation scores and first analgesic demand

\begin{tabular}{|c|c|c|c|}
\hline & $\begin{array}{c}\text { Group-D } \\
\text { Dexmedetomidine } \\
(n=30)\end{array}$ & $\begin{array}{c}\text { Group-E } \\
\text { Esmolol }(n=30)\end{array}$ & $P$ value \\
\hline Aldrete's score $\geq 9$ (min) & $10.4 \pm 2.5$ & $8.5 \pm 2.3$ & $<0.01^{\mathrm{s}}$ \\
\hline $\begin{array}{l}\text { Sedation score } 10 \mathrm{~min} \\
\text { after surgery }\end{array}$ & $4.0 \pm 0.6$ & $2.5 \pm 0.4$ & $<0.01^{\mathrm{s}}$ \\
\hline & & & $<0.01^{\mathrm{s}}$ \\
\hline $\begin{array}{l}\text { Sedation score } 20 \text { min } \\
\text { after surgery }\end{array}$ & $3.8 \pm 0.4$ & $2.3 \pm 0.2$ & $<0.01^{\mathrm{s}}$ \\
\hline $\begin{array}{l}\text { Sedation score } 30 \mathrm{~min} \\
\text { after surgery }\end{array}$ & $3.6 \pm 0.5$ & $2.1 \pm 0.3$ & $0.34^{\mathrm{NS}}$ \\
\hline $\begin{array}{l}\text { Sedation score } 40 \mathrm{~min} \\
\text { after surgery }\end{array}$ & $2.7 \pm 0$. & $2.1 \pm 0.5$ & $0.22^{\mathrm{NS}}$ \\
\hline $\begin{array}{l}\text { Sedation score } 60 \text { min } \\
\text { after surgery }\end{array}$ & $2.5 \pm 0.4$ & $2.0 \pm 0.5$ & \\
\hline $\begin{array}{c}1^{\text {st }} \text { analgesic demand } \\
(\min )\end{array}$ & $58.65 \pm 8.22$ & $31.25 \pm 5.15$ & \\
\hline
\end{tabular}

All values were presented as mean $\pm S D$ or in frequencies; Data were analysed using unpaired student ttest. Statistically significance was set at $p$-value $<0.05$. (NS=not significant, $S=$ significant). 


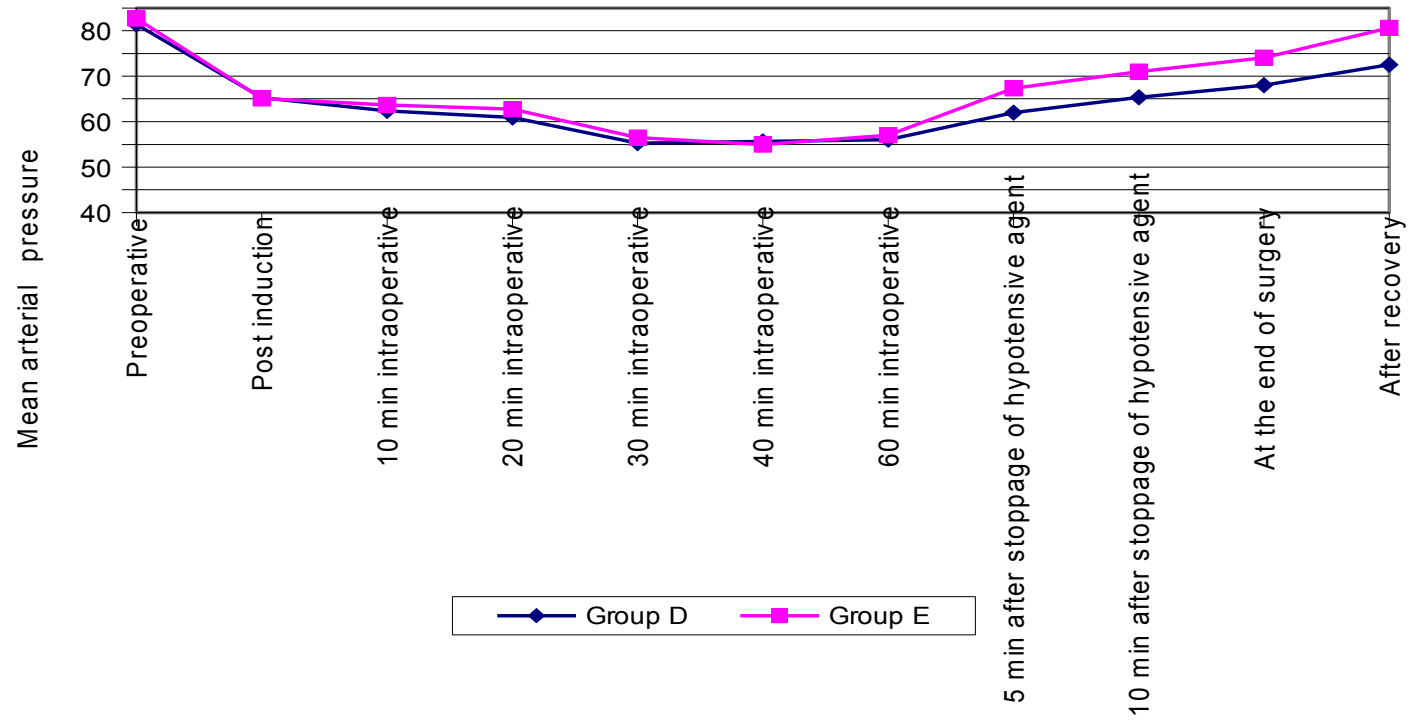

Figure-1 Line diagram showing intraoperative mean arterial blood pressure (MAP) in two groups

The mean arterial blood pressure at different time in between two groups which showed statistical significant at 5 minutes and 10 minutes after stoppage of hypotensive agents, at the end of surgery and after recovery and MAP was significantly lower in group $D$ than group $E(p<0.05)$

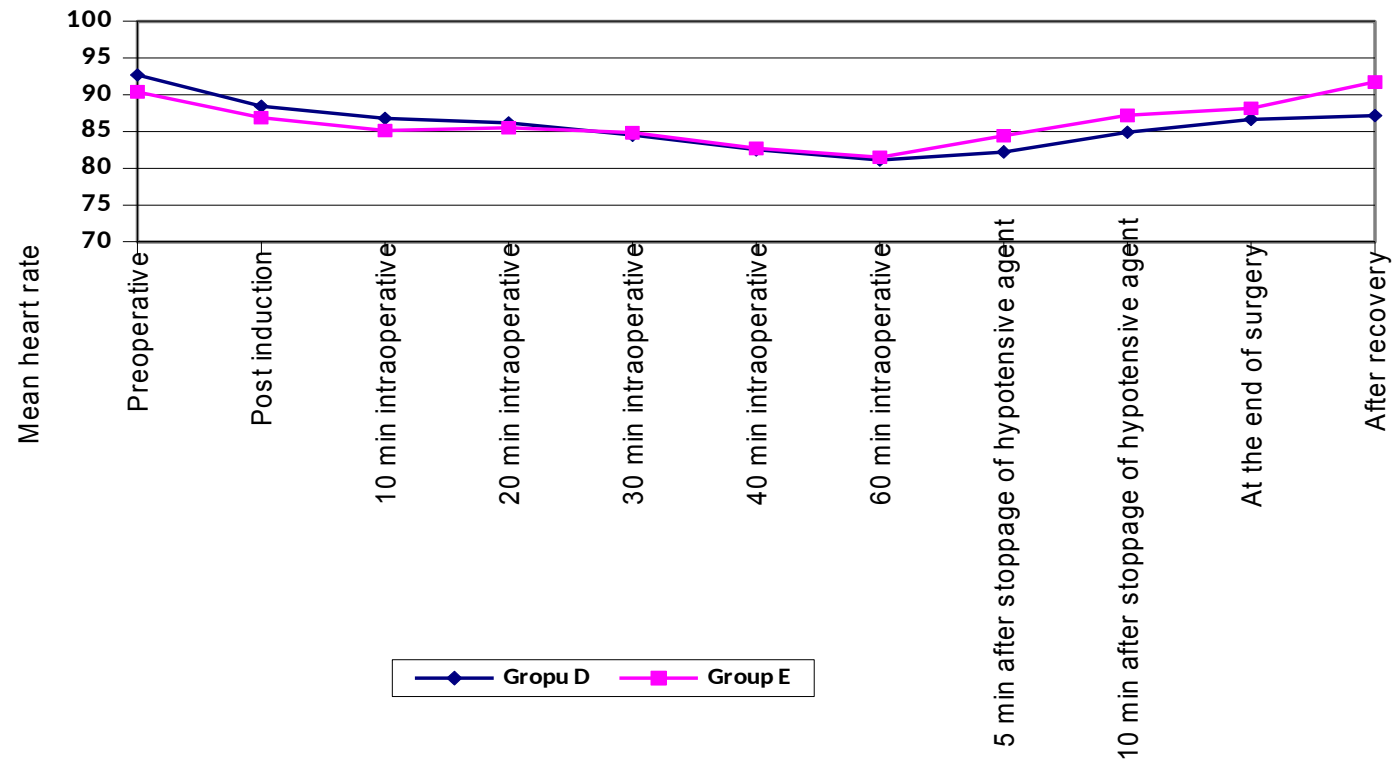

Figure-2: Line diagram showing intraoperative heart rate in two groups

The mean heart rate at different time in between two groups which showed significant increase in group $E$ at $5 \& 10$ minutes after stoppage of hypotensive agent, at the end of surgery and after recovery compared to group $D(p<0.05)$ 


\section{Discussion}

The development of a nasal endoscope has facilitated the surgical treatment (FESS) of acute and chronic sinus pathologies when conservative treatment fails. The procedure perpetuates the mucociliary clearance mechanism and conserves the normal nonobstructing anatomic structures. However, major or minor complications could occur as bleeding reduces the visibility of the operative field and hampers the surgical intervention.

There are a lot of efforts have been done to optimize the surgical conditions for FESS. Induced hypotension has been widely used to control bleeding during FESS to improve the quality of surgical field. ${ }^{13,}{ }^{14}$ Our study of dexmedetomidine or esmolol we planned to provide this optimal surgical field. Both drugs were effective providing MAP of $55-65 \mathrm{mmHg}$, and lowering the heart rate ensured good surgical condition and providing dry surgical field during FESS.

The patients who were treated with dexmedetomidine 10 minute before induction of anesthesia had significant decrease in MAP and HR after administration of loading dose. Dexmedetomidine is a potent highly selective $\alpha_{2-}$ adrenergic receptor agonist. It has sedative, analgesic and anesthetic sparing effect, and sympatholytic properties. ${ }^{15}$ The use of $\alpha_{2}$ adrenergic agonist cause decrease in sympathetic tone that causes decrease in heart rate, blood pressure and hemodynamic response to surgery. ${ }^{16}$ The analgesic and hypnotic effects of dexmedetomidine and other $\alpha_{2^{-}}$agonists is due to its action at locus coeruleus in the upper brain stem. ${ }^{17}$ The $\alpha_{2}-$ receptors are also involved in regulating the autonomic and cardiovascular systems. These $\alpha_{2}$ receptors are located on blood vessels, where they mediate vasoconstriction, and on sympathetic terminal, where they inhibit, norepinephrine release. ${ }^{18}$

Basar et al. ${ }^{19}$ provided the effect of single dose of dexmedetomidine $0.5 \mu \mathrm{g} / \mathrm{kg}$ administration 10 minute before induction of anesthesia and reported significant reduction in MAP and HR. The efficacy of dexmedetomidine in providing better surgical and less blood loss during controlled hypotension was previously reported during tympanoplasty, septoplasty and maxillofacial surgery. ${ }^{20,21}$ In the present study, the induction dose of propofol was significantly lower in group $D$ than in group $E$. This effect coinciding with the result of Peden et al. ${ }^{22}$, who reported that dexmedetomidine caused a reduction in the overall dose of Propofol required to produce loss of consciousness. Guven et al. ${ }^{23}$ and Goksu et al. ${ }^{24}$ found that better hemodynamic stability, visual analogue scale for pain and clear surgical field with less side effects in dexmedetomidine group than placebo group when FESS done under either conscious sedation or local anesthesia respectively.

Esmolol lowers arterial blood pressure through a decrease in cardiac output secondary to negative chronotropic and inotropic effects of $\beta$ - 
adrenergic antagonism. It provides a stable course of controlled hypotension and produces beneficial effects in the surgical fields and in blood conservation. ${ }^{25}{ }^{26}$ Esmolol has been used effectively to provide controlled hypotension intraoperatively in many studies. ${ }^{27}$ Lim et al. ${ }^{28}$ used esmolol for controlled hypotension in patients undergoing spinal surgery. They reported that esmolol was an appropriate agent for controlled hypotension in acute normovolemic hemodilution from the prevention of blood loss in patients except those who do not have cardiovascular problems. Esmolol provided a stable course of controlled hypotension and produces beneficial effects in the surgical field and in blood conservation. The optimal anesthetic technique seems to be relative bradycardia with associated hypotension. ${ }^{29}$

In our study intraoperative fentanyl consumption was significantly less in group D compared with group E. Several studies have found that perioperative use of dexmedetomidine was associated with a significant decrease in the consumption of inhalational agent, fentanyl, and analgesic in dose dependent manner. ${ }^{30,31}$

Our study also showed that postoperative analgesia requirement was prolonged in group $D$ than group E. This is accordance with Gurbet et al. ${ }^{32}$ who stated that intraoperative infusion of dexmedetomidine reduces perioperative analgesic requirements. The analgesic effects of dexmedetomidine had been appreciated in various setting and various populations. ${ }^{33}, 34$ Dexmedetomidine was associated with significant longer recovery time from anesthesia.

\section{Conclusion}

In conclusion, our study was the first study conducted in Bangladesh population and this study demonstrated that dexmedetomidine or esmolol both were safe agents for controlled hypotension and both were effective in providing ideal surgical field during FESS. But compared with esmolol dexmedetomidine offers the advantage of inherent analgesic, sedative and anesthetic sparing effect.

\section{References}

1. Shams T, El Bahnasawe NS, AbuSamra M, El-Masry R. Induced hypotension for functional endoscopic sinus surgery: a comparative study of dexmedetomidine versus esmolol. Saudi J Anaesth 2013 Apr; 7(2): 175 - 180

2. Elsharnouby NM, El Sharnouby MM. Magnesium sulphate as a technique of hypotensive anesthesis. $\mathrm{Br} \mathrm{J}$ Anaesth 2006; 96: 727 - 31

3. Degoute CS, Ray MJ, Manchon M, Dubreuil C, Banssillon V. Remifentanil and controlled hypotension; comparison with nitropruside or esmolol during tympanoplasty. Can J Anaesth 2001; 48: $20-7$

4. Degoute CS, Dubreuil C, Ray MJ, Guitton J, Manchon M, Banssillon V. Effect of posture, hypotension and locally applied vasoconstriction on the middle ear microcirculation in anaesthetized humans. Eur $\mathrm{J}$ Appl Physiol Occup Physiol 1994; 69: 414 20

5. Pavlin JD,Colley PS, Weymuller EA Jr, Van Norman G, Gunn HC. Propofol 
versus isoflurane for endoscopic sinus surgery. Am J Otolaryngol 1999; 20: 96 $-101$

6. Degoute CS. Controlled hypotension: Guide to drug choice. Drugs 2007; 67: $1053-76$

7. Abdullah $\mathrm{AO}$, Yaman $\mathrm{O}$, Ayten $\mathrm{S}$, Hakan E, Hiisnti S, Giilten A, et al. Dexmedetomidine versus remifentanil for controlled hypotensive anesthesia in functional endoscopic sinus surgery. Turk J Anaesth Reanim 2012; 40: 257 261

8. Lee J, Kim Y, Park C, Jeon Y, Kim D, Joo J, Kang H. Comparison between dexmedetomidine and remifentanil for controlled hypotension and recovery in endoscopic sinus surgery. Ann Otol Rhinol Laryngol 2013; 122: 421 - 426

9. Sudhesh $\mathrm{K}$ Hassoor SS. Dexmedetomidine in anesthesia practice: a wonder drug? Indian J Anaesth 2011; 55: 323 - 324

10. Fromme GA, MacKenzie RA, Gould AB Jr, Lund BA, Offord KP. Controlled hypotension for orthognatic surgery. Anesth Analg 1986; 65: 683 - 6

11. Alderete JA. The post-anesthesia recovery score revisted. J Clin Anesth1995; 7: 89

12. Ramsay $M$, Savege $T$, Simpson $B R$, Good R. Controlled sedation with alphaxolone-alphadolone. $\mathrm{Br}$ Med J 1974; 2: 656 - 9

13. Eberhart LH, Folz BJ, Wulf $H$, Geldner G. Intravenous anesthesia provides optimal surgical conditions during microscopic and endoscopic sinus surgery. Laryngoscope 2003; 113: 1369 $-73$

14. Cincikas D, Ivaskevicius S. Application of controlled arterial hypotension in endoscopic rhino-surgery. Medicina (Kaunas) 2003; 39: 852 - 9

15. Bloor BC, Ward DS, Belleville JP, Maze M. Effect of intravenous dexmedetomidine in humans. Hemodynamic changes. Anesthesiology.1992; 77: 1134 - 42

16. Muzi M, Goff DR, Kampine JP, Roerig DL, Ebert TJ. Clonidine reduces sympathetic activity but maintains baroreflex responses in normotensive humans. Anesthesiology. 1992; 77: 864 $-71$

17. Mariappan $\mathrm{R}$, Narayana Prabhu $\mathrm{AH}$, Kuppuswamy B. Comparing the effects of oral clonidine premedication with intraoperative dexmedetomidine infusion on anesthetic requirement and recovery from anesthesia in patients undergoing major spine surgery. J Neurosurg Anesthesiol. 2013 Jul 24

18. Langer SZ. Presynaptic regulation of the release of catecholamines. Pharmacol Rev 1980; 32: 337 - 62

19. Basar H, Akpinar S, Doganci N, Buyukkocak U, Kaymak C, Sert O,. The effect of preanaesthetic single dose of dexmedetomidine on induction, hemodynamic and cardiovascular parameters. J Clin Anesth 2008; 20: 431 $-6$

20. Durmus M, But AK, Dogan Z, Yucel A, 
Miman MC, Ersoy MO. Effect of dexmedetomidine on bleeding during tympanoplasty or septoplasty. Eur J Anaesthesiol 2007; 24: 447 - 53

21. Richa F, Yazigi A, Hage $C$. Dexmedetomidine an agent for controlled hypotension in maxilla fascial surgery. Eur J Anaesthesiol 2004; 21: A242

22. Peden CJ, Cloote AH, Stratford N, PrysRoberts C. The effect of intravenous dexmedetomidine premedication on the dose of requirements of propofol to induce loss of consciousness in patients receiving alfentanil. Anaesthesia 2001; 56: $408-13$

23. Guven DG, Demiraran Y, Sezen G, Kepek O, Iskender A. Evaluation of outcomes in patients given dexmedetomidine in functional endoscopic sinus surgery. Ann Otol Rhinol Laryngol 2011; 120: 586 - 92

24. Goksu S, Arik H, Demiryurek S, Mumbuc S, Oner U, Demiryurek AT. Effects of dexmedetomidine infusion in patients undergoing functional endoscopic sinus surgery under local anaesthesia. Eur J Anaesthesiol 2008; 25: $22-8$

25. Degoute CS, Ray MJ, Manchon $M$, Dubreuil C, Banssillon V. Remifentanil and controlled hypotension; comparison with nitropruside or esmolol during tympanoplasty. Can J Anesth. 2001; 48: $20-7$

26. Boezaart AP, Merwe JV, Coetzee A. Comparison of sodium nitropruside and esmolol-induced controlled hypotension for functional endoscopic sinus surgery. Can J Anesth. 1995; 42: 373 - 6

27. Ibraheim OA, Abdulmonem A, Baaj J, Zahrani TA, Arlet V. Esmolol versus dexmedetomidine in scoliosis surgery: study on intraoperative blood loss and hemodynamic changes. Middle East J Anesthesiol. 2013 Feb; 22(1): 27 - 33

28. Lim YZ, Kim CS, Bahk JH, Ham BM, Do $\mathrm{SH}$. Clinical trial of esmolol induced controlled hypotension with or without acute normovolemic hemodilution in spinal surgery. Acta Anesthesiol Scand. 2003; 47: 74 - 8

29. Timperley D, Sacks R, Parkinson RJ, Harvey RJ. Perioperative and intraoperative maneuvers to optimize surgical outcomes in skull base surgery. Otolaryngol Clin North Am 2010; 43: $699-730$.

30. Aantaa R, Jaakola ML, Kallio A, Kanto J. Reduction of the minimum alveolar concentration of isoflurane by dexmedetomidine. Anesthesiology 1997; 86: 1055 - 60

31. Scheinin H, Jaakola ML, Sjovall S, AliMelkkila T, Kaukinen S, Turunen J. Intramuscular dexmedetomidine as premedication for general anaesthesia. A comparative multicenter study. Anesthesiology 1993; 78: 1065 - 75

32. Gurbet A, Basagan-Mogol E, Turker G, Ugun F, Kaya FN, Ozcan B. Intraoperative infusion of dexmedetomidine reduces perioperative analgesic requirements. Can J Anesth 
2006; 53: 646 - 52

33. Huncke TK, Adelman M, Jacobowitz, G Maldonado T, Bekker A. A prospective randomized, placebo- controlled study evaluating the efficacy of dexmedetomidine for sedation during vascular procedures. Vasc Endovasc Surg 2010; 44: 257 - 61

34. Karaaslan K, Yilmaz F, Gulcu N, Colak
C, Sereflican M, Kocoglu H. Comparison of dexmedetomidine and midazolam for monitored anaesthesia care combined with tramadol via patient - controlled analgesia in endoscopic nasal surgery: A prospective randomized, double-blind, clinical study. Curr Ther Res Clin Exp 2007; 68: 69 - 81 